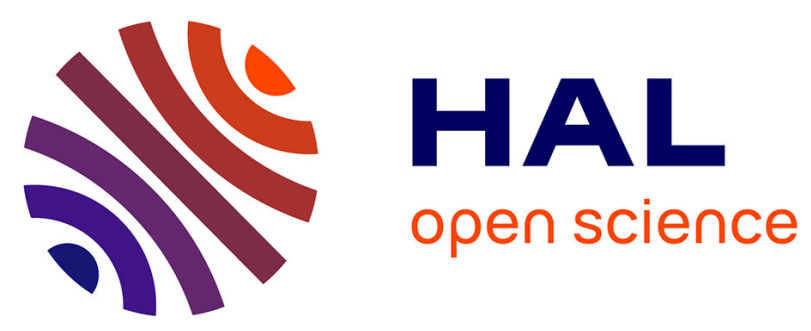

\title{
Novel Porous Carbon Material for the Detection of Traces of Volatile Organic Compounds in Indoor Air
} Achraf El Mohajir, Jimena Castro-Gutiérrez, Rafael Luan Sehn Canevesi, Igor

Bezverkhyy, Guy Weber, Jean-Pierre Bellat, Franck Berger, Alain Celzard, Vanessa Fierro, Jean-Baptiste Sanchez

\section{To cite this version:}

Achraf El Mohajir, Jimena Castro-Gutiérrez, Rafael Luan Sehn Canevesi, Igor Bezverkhyy, Guy Weber, et al.. Novel Porous Carbon Material for the Detection of Traces of Volatile Organic Compounds in Indoor Air. ACS Applied Materials \& Interfaces, 2021, 13 (33), pp.40088-40097. 10.1021/acsami.1c10430 . hal-03387839

\section{HAL Id: hal-03387839 \\ https://hal.univ-lorraine.fr/hal-03387839}

Submitted on 20 Oct 2021

HAL is a multi-disciplinary open access archive for the deposit and dissemination of scientific research documents, whether they are published or not. The documents may come from teaching and research institutions in France or abroad, or from public or private research centers.
L'archive ouverte pluridisciplinaire HAL, est destinée au dépôt et à la diffusion de documents scientifiques de niveau recherche, publiés ou non, émanant des établissements d'enseignement et de recherche français ou étrangers, des laboratoires publics ou privés. 


\title{
A Novel Porous Carbon Material for the Detection of Traces of Vola- tile Organic Compounds in Indoor Air
}

\author{
Achraf El Mohajir ${ }^{\text {a }}$, Jimena Castro-Gutiérrez ${ }^{\mathrm{b}}$, Rafael Luan Sehn Canevesi ${ }^{\mathrm{b}}$, Igor Bezverkhyy ${ }^{\mathrm{c}}$, Guy \\ Weber $^{c}$, Jean-Pierre Bellat ${ }^{c}$, Franck Berger ${ }^{a}$, Alain Celzard ${ }^{b}$, Vanessa Fierro ${ }^{\text {b, }}$, Jean-Baptiste \\ Sanchez ${ }^{\text {a,* }}$ \\ ${ }^{a}$ Institut FEMTO-ST, UMR 6174 CNRS, Université de Bourgogne - Franche-Comté, 15B, Avenue des Montboucons, \\ 25030 Besançon Cedex, France \\ ${ }^{\mathrm{b}}$ Université de Lorraine, CNRS, IJL, F-88000, Épinal, France \\ ${ }^{\mathrm{c}}$ Laboratoire Interdisciplinaire Carnot de Bourgogne, UMR 6303 CNRS, Université de Bourgogne - Franche Comté, 9 Ave- \\ nue Alain Savary, BP 47870, 21078 Dijon, France.
}

\begin{abstract}
A highly sensitive and selective silicon-based micro-analytical prototype was used to identify a few ppb of volatile organic compounds (VOCs) in indoor air. Herein, a new non-activated tannin-derived carbon synthesized by an environmentally friendly method, DM2C, a MIL-101(Cr) MOF and a DaY zeolite were selected for the preconcentration of BTEX compounds (i.e. benzene, toluene, ethylbenzene and xylenes). Integrating a small amount of these nanoporous solids inside a miniaturized preconcentration unit led to excellent preconcentration performance. By taking advantage of the high adsorptiondesorption capacities of the DM2C adsorbent, concentrations as low as 23.5, 30.8, 16.7, 25 and $28.8 \mathrm{ppb}$ of benzene, toluene, ethylbenzene, ortho- and para-xylene, respectively, were detected in a short analysis time $(\sim 10 \mathrm{~min})$ even in the presence of $60 \%$ relative humidity at $25{ }^{\circ} \mathrm{C}$. The DM2C showed excellent stability, over a period of 4 months and more than 500 tests, as well as repeatability, which makes it a very reliable adsorbent for the detection of trace VOCs in indoor air under realistic conditions in the presence of humidity.
\end{abstract}

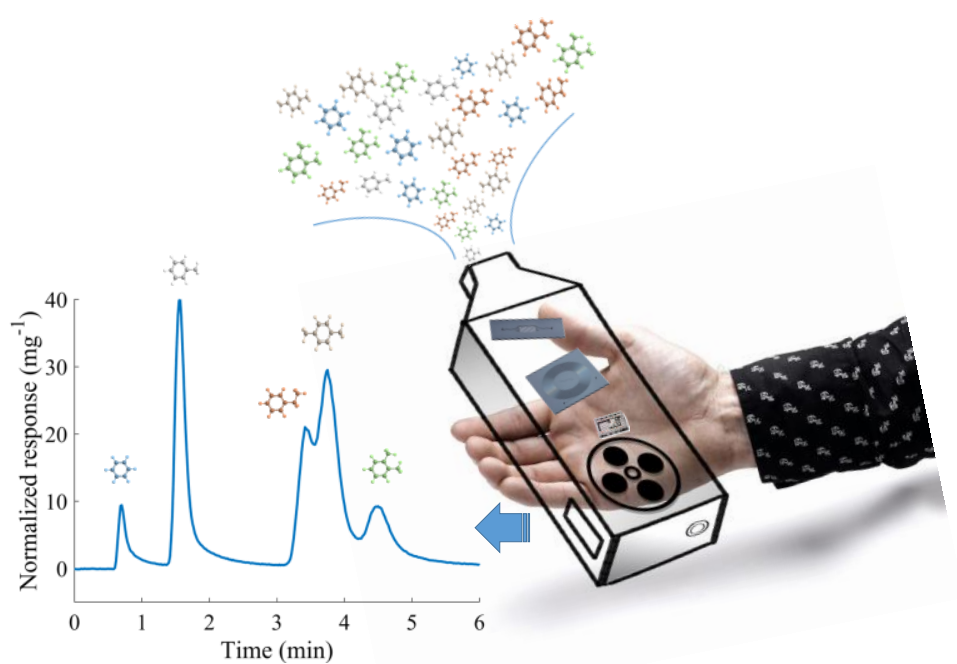

KEYWORDS: indoor air monitoring, BTEX, miniaturized gas chromatograph, preconcentrator, hydrophobic carbon, MOF, zeolite, microporous materials

\section{INTRODUCTION}

BTEX compounds (i.e., benzene, toluene, ethylbenzene and xylenes) are volatile organic compounds (VOCs) that have long been known to be carcinogenic to humans even at very low concentrations, near the ppb level [1-4]. Car exhaust, heavy industry and oil refineries are the main outdoor sources of these compounds [5-7]. On the other hand, the indoor load of these compounds is not only related to indoor activities such as smoking, cooking, heating or cleaning, but it is also partly influenced by outdoor conditions due to the penetration of ambient air pollutants into homes, especially when they are equipped with ventilation systems [8-10]. Therefore, indoor VOC levels are sometimes significantly higher than those found outdoors [11-12]. Studies have shown that concentrations of these compounds are generally between $0.1 \mathrm{ppb}$ and
$50 \mathrm{ppb}$ in indoor air [13-15]. Therefore, in situ detection and discrimination of these VOCs in a complex mixture such as ambient air is a relevant and challenging task. Although in the last two decades a real effort has been made to develop portable and low-cost sensors for indoor air quality monitoring, methods based on gas chromatography (GC) coupled with various detectors are still the most efficient techniques employed for BTEX detection [16-17]. Despite their high analytical performance in terms of sensitivity and selectivity, these methods do not allow in situ analysis, mainly due to their large size, high energy and gas consumption, as well as complicated preventive maintenance. Consequently, the use of adsorbentfilled cartridges for air sampling is necessary prior to full laboratory analysis, which makes a real-time monitoring difficult [18]. 
Our research group has developed a silicon-based microanalytical prototype, which can be considered as miniaturized gas chromatograph for a real-time analysis [19]. This device consists of a gas micro-preconcentrator coupled to a siliconetched spiral GC micro-column and a metal oxide-based gas sensor. Previous studies have shown that this miniaturized device allows detecting compounds in complex mixtures within minutes [20]. Preconcentration of target molecules is essential for the detection of indoor VOCs, as the levels of these pollutants are very low and mostly below the limit of detection (LOD) of various detectors. Many materials have been investigated as candidate adsorbents for the preconcentration of compounds in the gas phase [21,22]. For this specific application and according to our previous studies, as the target gases are in very low concentration, the suitable adsorbent should have a sufficiently high adsorption affinity for VOCs, but not too high, in order to facilitate their desorption upstream the GC micro-column [23]. The adsorption-desorption process must be reversible and as fast as possible. Small pore adsorbents will be preferred because the adsorption forces are enhanced in narrow pores, provided that VOC diffusion in the porosity is not affected. In addition, as ambient air is never dry, the adsorbents must be hydrophobic in order to avoid any competitive adsorption between water and VOCs.

Zeolites and activated carbon materials have been widely studied for this application due to their highly developed porous texture and good adsorption performance [24, 25]. More recently, Metal Organic Frameworks (MOFs) have attracted attention as they offer many advantageous features, including high specific surface area, tailorable porosity and surface chemistry, structural diversity and interesting gas/vapor adsorption properties [26-28]. These hybrid porous materials are formed by self-assembly between metal ions and organic ligands, resulting in permanent porosity [29, 30]. Although extensive studies have been done on the capture of harmful or toxic gases/vapors (e.g. benzene, toluene, xylene and linear hydrocarbons) by MOFs, especially MIL-101(Cr) [31-33], few researches address the preconcentration of BTEX. The use of these adsorbent materials has led to a significant breakthrough in detection limits, allowing ppb-levels to be achieved, i.e., close to those found in indoor air [34-35]. However, systems capable of measuring these concentrations with a relatively short analysis time are still in an early development phase and remain confined to research laboratories.

The present work investigates the adsorption/desorption capacities of three types of nanoporous materials for the preconcentration and identification of BTEX in indoor air using a miniaturized analyzer. A zeolite, DaY, a MOF, MIL$101(\mathrm{Cr})$, and a non-activated, tannin-derived micromesoporous carbon, DM2C, were chosen based on their pore volume, pore size distribution and surface properties. All three of these materials have a pore diameter larger than the kinetic diameter of BTEXs and exhibit sufficiently high adsorption affinity to capture these pollutants at very low concentrations while allowing near complete desorption upon heating. After characterizing the textural properties of the selected materials, we first studied their adsorption properties in pure gas phase, for toluene and water using the thermo gravimetric technique. Then, the adsorption/desorption capacities of each adsorbent material for the preconcentration of indoor air pollutants were studied using the miniaturized analytical prototype. Specifically, a mixture of five different VOCs, i.e., benzene, toluene, ethylbenzene and ortho-/para-xylene, was selected as repre- sentative of aromatic indoor air pollutants in this study. In addition, the influence of relative humidity $(\mathrm{RH})$ ranging from $2 \%$ to $60 \%$ at $25{ }^{\circ} \mathrm{C}$ was investigated to reproduce the indoor air environment. Here, we have demonstrated the interest of using porous solids, in particular the DM2C material, to achieve rapid detection and quantification of indoor air pollutants present even at very low concentrations.

\section{EXPERIMENTAL SECTION}

2.1. Adsorbents. Three adsorbents were investigated for the preconcentration of the selected BTEX compounds in indoor air:

A hydrophobic dealuminated faujasite zeolite supplied by Degussa and referenced as DaY. Its chemical formula is $\mathrm{Na}_{2}\left(\mathrm{Al}_{2} \mathrm{Si}_{190} \mathrm{O}_{384}\right)$ and the particle size was in the $1-5 \mu \mathrm{m}$ range.

- A chromium terephthalate metal-organic framework referenced as MIL-101(Cr) with a chemical formula $\mathrm{Cr}_{3}(\mathrm{OH})\left(\mathrm{H}_{2} \mathrm{O}\right)_{2} \mathrm{O}(\mathrm{bdc})_{3} \sim 25 \mathrm{H}_{2} \mathrm{O}$ (bdc = 1,4-benzene dicarboxylate). This material was synthesized at the National Institute for Research and Development of Isotopic and Molecular Technologies (Cluj-Napoca, Romania). The synthesis is based on the reaction between $\mathrm{CrCl}_{3}$ and $\mathrm{H}_{2}$ bdc in a fluoride-free aqueous solution under hydrothermal conditions at $210^{\circ} \mathrm{C}$. Details of the synthesis can be found in [36].

- $\quad$ A hydrophobic disordered micro-mesoporous carbon prepared by a surfactant-water-assisted mechanochemical mesostructuration (SWAMM) method from mimosa tannin and referenced as $\mathrm{DM} 2 \mathrm{C}$ in this study but originally labeled CT2P2W2_60 in [37]. Its composition is $\mathrm{C}_{7.5} \mathrm{O}_{0.6} \mathrm{H}_{0.7}$. Briefly, the synthesis was carried out in a planetary ball-mill (PM 100, Retsch) where mimosa tannin, Pluronic ${ }^{\circledR}$ F127 and water (2 g of each) were milled for $1 \mathrm{~h}$, and the retrieved material was directly submitted to carbonization at $900{ }^{\circ} \mathrm{C}$ under nitrogen flow to obtain the carbon material. More details can be found elsewhere [37]. Unlike most carbons used for the preconcentration of pollutants, DM2C did not undergo any activation step to develop its porous texture.

2.2. Characterization of the porosity of the adsorbents. The pore textural properties of the adsorbents were characterized by $\mathrm{Ar}$ adsorption-desorption isotherms at $-186{ }^{\circ} \mathrm{C}$ using an automatic 3-Flex adsorption device (Micromeritics) equipped with a helium cryostat to control the temperature. Before any gas adsorption, the porous solids were outgassed at $110^{\circ} \mathrm{C}$ under secondary vacuum for at least $48 \mathrm{~h}$. Then, Ar isotherms were measured up to the atmospheric pressure. The BET area, $A_{B E T}$, was calculated by applying the BET equation to the $\mathrm{Ar}$ adsorption branch in the adequate pressure range [38]. The 2D non-local density functional theory for heterogeneous surfaces (2D-NLDFT HS) was applied to the Ar data in order to calculate the pore size distributions (PSDs) of the adsorbents. By integration of the PSD, we obtained the total pore volume, $V_{T}$, the micropore volume, $V_{\mu}$, and the mesopore volume, $V_{m}$, was calculated as the difference between $V_{T}$ and $V_{\mu}$. The PSD was also used to calculate the volume under a given pore size.

2.3. Toluene and water adsorption properties. In addition, toluene and water adsorption/desorption isotherms were measured at $25{ }^{\circ} \mathrm{C}$ by thermogravimetry (McBain type thermobalance) under controlled vapor pressure. The experimental set-up and the preparation of the organic adsorptive are described in detail in [39]. 


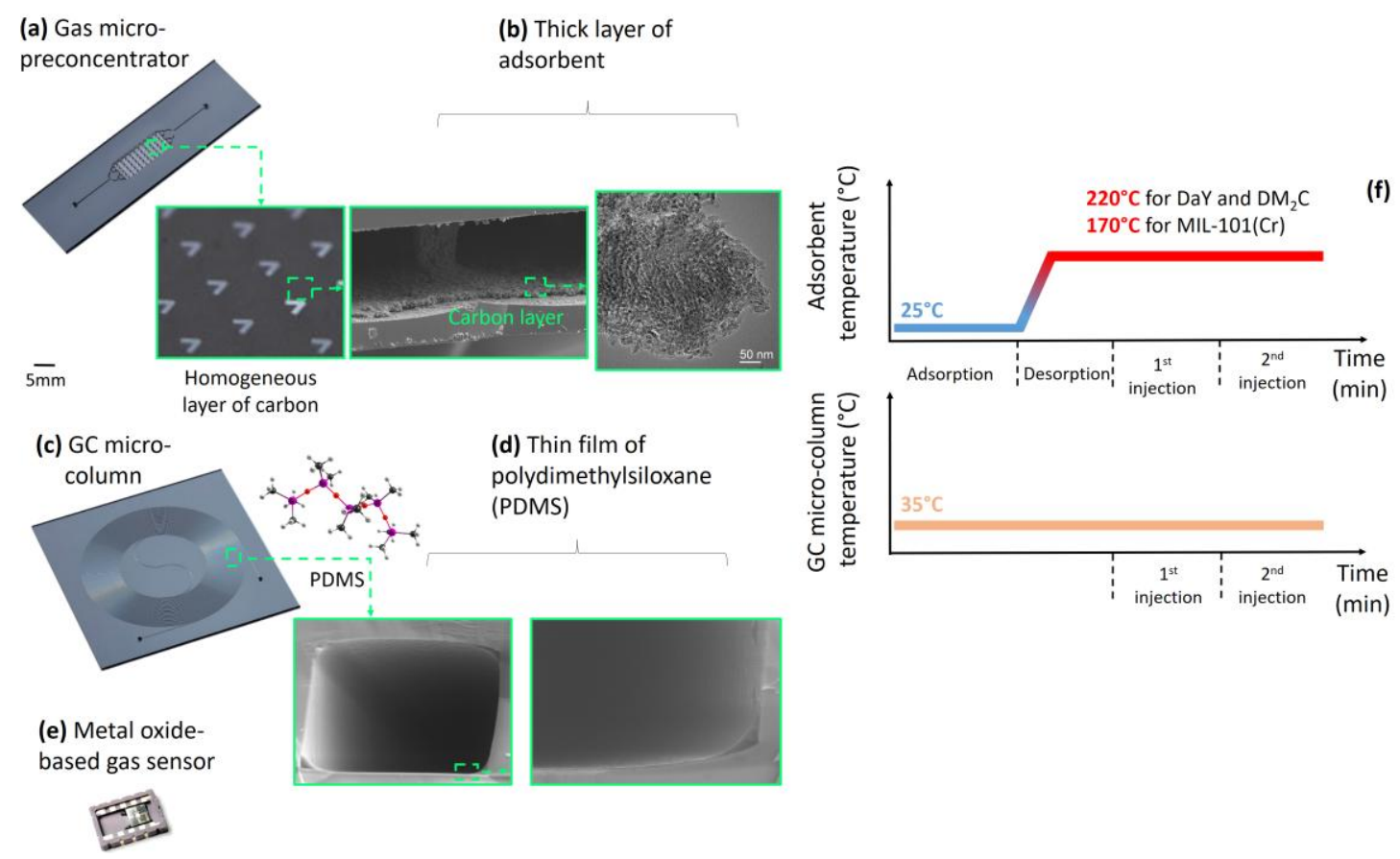

Figure 1. (a) Silicon gas micro-preconcentrator; (b) thick layer of adsorbent: the cross-sectional SEM picture shows an example of the DM2C layer; (c) silicon gas chromatography (GC) micro-column; (d) cross-sectional SEM picture of the $100 \mathrm{~nm}$ PDMS stationary phase film; (e) tin oxide-based gas sensor. (f) Testing procedure: each step is schematized along with the evolution of temperature over time.

The sample (around $15 \mathrm{mg}$ ) was first evacuated in situ under dynamic vacuum $\left(10^{-5} \mathrm{hPa}\right)$ for $16 \mathrm{~h}$ at $400{ }^{\circ} \mathrm{C}$ for $\mathrm{DaY}$ and $\mathrm{DM} 2 \mathrm{C}$, and at $25^{\circ} \mathrm{C}$ for MIL-101(Cr). Then, the sample was cooled down to $25{ }^{\circ} \mathrm{C}$ and the adsorption/desorption isotherms were measured step-by-step using a static method by introducing successively doses of toluene or water vapor into the thermobalance. Once a constant mass was reached, the next equilibrium state was performed by slightly increasing or decreasing the vapor pressure. The vapor pressure ranged from $10^{-4}$ to about $30 \mathrm{hPa}$.

2.4. Description of the miniaturized analyzer and testing procedure. Figure 1 shows each analytical unit composing the silicon-etched micro-analytical prototype used to identify low concentrations of BTEX in indoor air. These units were connected together by silica capillaries and a six-way valve equipped with a $200 \mu \mathrm{L}$ sampling loop [19]. Each selected adsorbent was deposited as a thick and homogeneous layer inside the gas micro-preconcentrators (Figures 1 (a) and 1 (b)) according to a method explained elsewhere [19, 20]. The amount of adsorbent weighed after the deposition in each gas micro-preconcentrator was $1.2,0.8$ and $0.2 \mathrm{mg}$ for DaY, MIL$101(\mathrm{Cr})$ and DM2C, respectively. The inner wall of the 5-m long column (Figure 1 (c)) was covered with a thin film of polydimethylsiloxane (PDMS) stationary phase (Figure 1 (d)) to separate all desorbed BTEX compounds from the micropreconcentrator. Finally, a miniaturized tin oxide-based gas sensor (Figure 1 (e)) was used as a detector.

The testing procedure is schematized in Figure 1 (f) along with the temperature evolution over time. First, the adsorbent was exposed to a mixture of BTEX compounds at $25{ }^{\circ} \mathrm{C}$ and at a flow rate of $40 \mathrm{~mL} \min ^{-1}$ for 5 min (adsorption step). The BTEX compounds were generated by permeation and their initial concentrations in air were $2.35,3.08,1.67,2.50$ and $2.88 \mathrm{ppm}$ for benzene, toluene, ethylbenzene, ortho and paraxylene, respectively. After the adsorption step, the adsorbent was heated at $170{ }^{\circ} \mathrm{C}$ for MIL-101(Cr) and $220{ }^{\circ} \mathrm{C}$ for DaY and $\mathrm{DM} 2 \mathrm{C}$ using a PID temperature controller (heating rate $5.5^{\circ} \mathrm{C} \mathrm{s}^{-1}$ ), in order to desorb the concentrated VOCs towards the GC micro-column. For the MOF, the maximum desorption temperature was lower in order to avoid its thermal decomposition. After a certain time, called "desorption time", ranging from 0.25 to $2.5 \mathrm{~min}$, the desorbed analytes were injected, through the injection valve, into the silicon GC micro-column heated at $35{ }^{\circ} \mathrm{C}$. The carrier gas flow rate inside the GC micro-

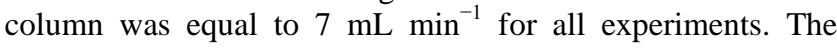
variation in the sensor response $\left(\mathrm{S}=\left(\mathrm{G}-\mathrm{G}^{\circ}\right) / \mathrm{G}^{\circ}\right)$ as a function of time served as the detection signal for the system, where $G$ is the conductance under the BTEX compounds, and $\mathrm{G}^{\circ}$ is the conductance under carrier air flow. To compare the detection performance of the system, we plotted the evolution of the sensor response $\mathrm{S}$, normalized per $\mathrm{mg}$ of adsorbent $(\mathrm{S} / \mathrm{m})$, as a function of time. In order to assess the presence of residual compounds desorbed from the gas micro-preconcentrator, the latter was held at the maximum desorption temperature during the separation and detection phase; then, a second injection was performed after the complete elution of all analytes from the first injection. The experiments were first conducted in nearly dry air $\left(2 \% \mathrm{RH}\right.$ at $\left.25{ }^{\circ} \mathrm{C}\right)$, and then the influence of water vapor on the adsorption capacities of porous materials was

also evaluated. 

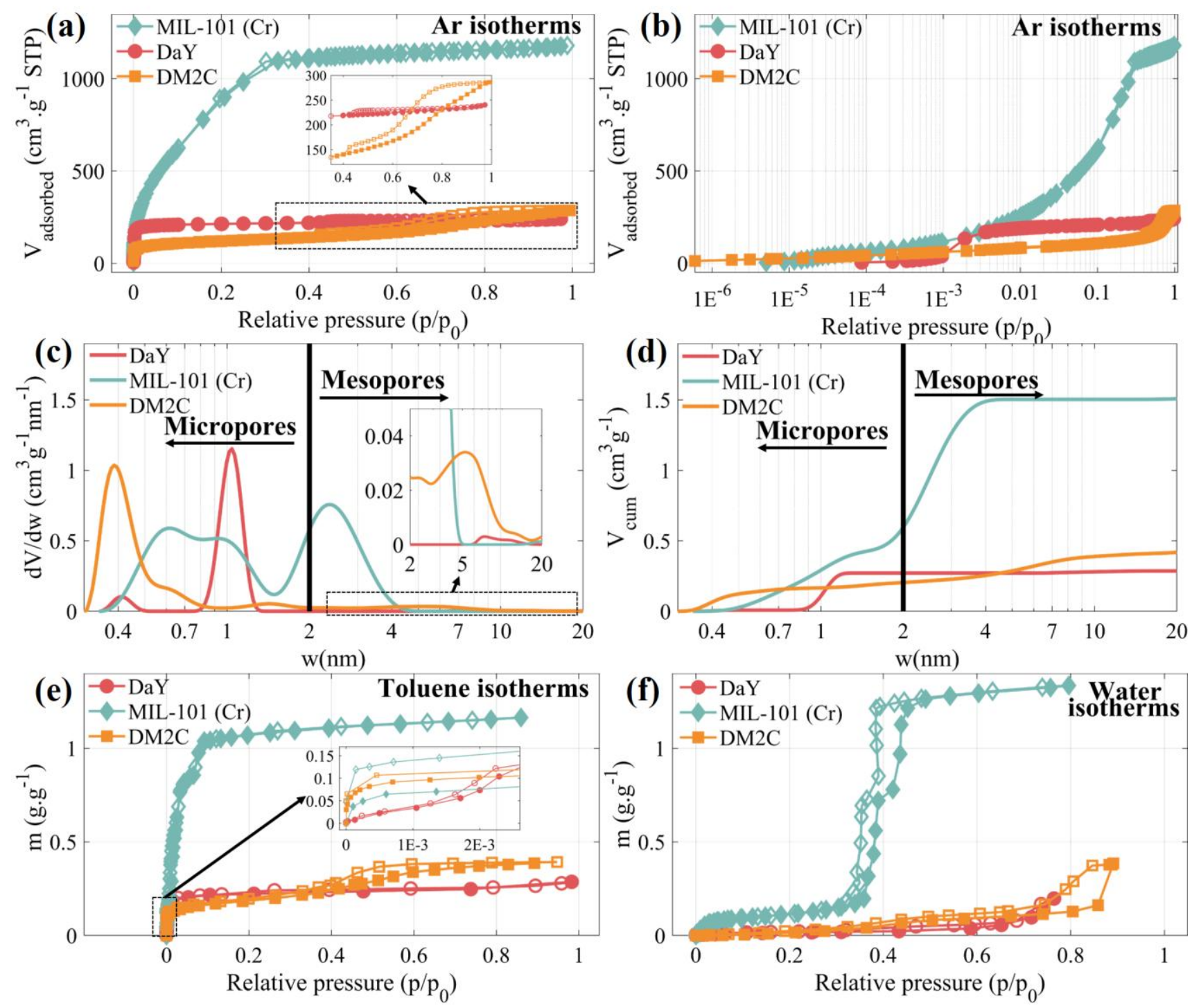

Figure 2. Adsorption - desorption isotherms of $\mathrm{Ar}$ on the DM2C carbon, DaY zeolite and MIL-101(Cr) $\mathrm{MOF}$ at $-186{ }^{\circ} \mathrm{C}$ in (a) linear scale and (b) logarithmic scale. (c) Differential and (d) cumulative pore size distributions obtained by applying the 2D NLDFT HS model to the Ar adsorption data. (e) Toluene and (f) water adsorption - desorption isotherms on the three selected materials at $25^{\circ} \mathrm{C}$. Full symbols: adsorption; empty symbols: desorption.

Table 1. Composition and textural properties of the selected adsorbents.

\begin{tabular}{|c|c|c|c|c|c|c|c|}
\hline Adsorbent & Structure & Formula & $\begin{array}{c}A_{B E T} \\
\left(\mathrm{~m}^{2} \mathrm{~g}^{-1}\right)\end{array}$ & $\begin{array}{c}V_{T} \\
\left(\mathrm{~cm}^{3} \mathrm{~g}^{-1}\right)\end{array}$ & $\begin{array}{c}V_{\mu} \\
\left(\mathrm{cm}^{3} \mathrm{~g}^{-1}\right)\end{array}$ & $\begin{array}{c}V_{\text {meso }} \\
\left(\mathrm{cm}^{3} \mathrm{~g}^{-1}\right)\end{array}$ & $\begin{array}{c}d_{m} \\
(\mathrm{~nm})\end{array}$ \\
\hline $\begin{array}{l}\text { Zeolite } \\
\text { DaY }\end{array}$ & & $\mathrm{Na}_{2}\left(\mathrm{Al}_{2} \mathrm{Si}_{190} \mathrm{O}_{384}\right)$ & 762 & 0.29 & 0.27 & 0.02 & 1.01 \\
\hline $\begin{array}{l}\text { MOF } \\
\text { MIL-101(Cr) }\end{array}$ & & $\mathrm{Cr}_{3}(\mathrm{OH})\left(\mathrm{H}_{2} \mathrm{O}\right)_{2} \mathrm{O}(\mathrm{bdc})_{3} \sim 25 \mathrm{H}_{2} \mathrm{O}$ & 3201 & 1.51 & 0.59 & 0.92 & 1.15 \\
\hline $\begin{array}{l}\text { Carbon } \\
\text { DM2C }\end{array}$ & & $\mathrm{C}_{7.5} \mathrm{O}_{0.6} \mathrm{H}_{0.7}$ & 382 & 0.44 & 0.20 & 0.24 & 0.65 \\
\hline
\end{tabular}

$A_{B E T}$ : BET area; $V_{T}$ : total pore volume; $V_{\mu}$ : micropore volume; $V_{\text {meso }}$ : mesopore volume approximated from the difference of $V_{T}$ and $V_{\mu}, d_{m}$ : average micropore diameter. $V_{T}, V_{\mu}$, and $d_{m}$ were determined by application of the 2D-NLDFT-HS model. 


\section{RESULTS AND DISCUSSION}

3.1. Pore structure of the adsorbents. Figure 2 (a) shows the Ar adsorption-desorption isotherms of the selected adsorbents labeled DaY, MIL-101(Cr) and DM2C. All materials exhibit a high argon uptake at low relative pressures $\left(p / p_{0}<0.01\right)$, confirming the existence of narrow micropores (see Figure 2 (b) for more details). DaY zeolite exhibits a small $\mathrm{H} 4$ hysteresis loop according to the IUPAC classification, where the adsorption branch is a combination of type I and II isotherms, associated with the presence of micropores and some mesopores [40].

On the other hand, the DM2C isotherm exhibits an adsorption branch resulting from the combination of type I and IVa isotherms, and an H5 hysteresis loop associated with micromesoporous materials with open and partially blocked mesopores with widths above $\sim 4 \mathrm{~nm}$ [40]. The MIL-101(Cr) presents an isotherm derived from the combination of types I and IVb found for micro-mesoporous materials with narrow mesopores (width $<4 \mathrm{~nm}$ ) [40]. Figure 2 (c, d) shows the differential and cumulative pore size distributions (PSDs) of the selected materials. DaY has a narrow PSD, in the micropore range, centered at $\sim 1 \mathrm{~nm}$, while DM2C and MIL101(Cr) materials feature more complex PSDs. DM2C exhibits a PSD with two distinct peaks, one in the micropore range, centered at $\sim 0.5 \mathrm{~nm}$, and a second broader peak in the mesopore range at $\sim 5 \mathrm{~nm}$, extending from $c a .3$ to $10 \mathrm{~nm}$. In contrast, MIL-101(Cr) has a PSD with two distinct broad peaks, one spanning of the micropore range from $c a$. 0.4 to 1.5 $\mathrm{nm}$ and the second centered at $2.4 \mathrm{~nm}$ and comprising both large micropores and narrow mesopores (width $<5 \mathrm{~nm}$ ). The textural properties of the selected adsorbents, determined from the analysis of the argon adsorption data, are reported in Table 1 .

The $A_{B E T}$ values are 382 and $762 \mathrm{~m}^{2} \mathrm{~g}^{-1}$ for DM2C and DaY, respectively, while MIL-101(Cr) reaches an $A_{B E T}$ of $3201 \mathrm{~m}^{2} \mathrm{~g}$ ${ }^{1}$ and exhibits significant mesoporosity $\left(0.92 \mathrm{~cm}^{3} \mathrm{~g}^{-1}\right)$, compared to the other materials. DaY has a high micropore volume, which represents more than $93 \%$ of the total pore volume, while the micropore volume of DM2C and MIL-101(Cr) only represents $45 \%$ and $39 \%$ of the total pore volume, respectively. The average micropore diameter is around $0.65 \mathrm{~nm}$ for DM2C and slightly higher for the other materials, around 1.01 and $1.15 \mathrm{~nm}$ for DaY and MIL-101(Cr), respectively.

Regarding the values of kinetic diameters of BTEX compounds $(0.535,0.525,0.58,0.68$ and $0.58 \mathrm{~nm}$ for benzene, toluene, ethylbenzene, ortho- and para -xylene, respectively [41]) it is worth noting that all molecules can enter the pores of the selected materials. Even though the DM2C material exhibits a narrower microporosity than that observed for the DaY and MIL-101(Cr) samples (see Table 1), the wellconnected micro-mesoporosity in DM2C could increase the accessibility of the micropores [42], which is necessary for trapping BTEX compounds at low concentrations.

3.2. Toluene and water adsorption under equilibrium conditions. Before evaluating the BTEX preconcentration performance of the selected adsorbents with the micro-analytical device and under dynamic conditions, toluene and water adsorption-desorption isotherms under equilibrium conditions were first measured in order to obtain more information on the adsorption capacities of these porous solids. Toluene, having an intermediate diameter, is chosen here as a representative
BTEX VOC. The complete adsorption-desorption isotherms of toluene on the porous solids studied are presented in Figure 2 (e). The toluene uptake at high relative pressure (saturation plateau) can be correlated with the accessible pore volume of the solids. Given the density of liquid toluene, $0.867 \mathrm{~g} \mathrm{~cm}^{-3}$, the amounts adsorbed at the plateau are: $1.33,0.45$ and 0.32 $\mathrm{cm}^{3} \mathrm{~g}^{-1}$ for MIL-101(Cr), DM2C and DaY, respectively. The highest value was observed for MIL-101(Cr) due to the very high porosity of this material (see Table 1), in agreement with the Ar adsorption data. However, this part of the isotherm is not relevant for the present study since our goal is the preconcentration of very low concentrations of BTEX compounds $\left(<1 \mathrm{ppm}\right.$ or $\sim 0.001 \mathrm{hPa}$ or $\left.\sim p / p_{0}=2.6 \times 10^{-5}\right)$. The analysis of the low-pressure part of the toluene isotherms (see insert in Figure 2 (e)) shows that the trend in this pressure range is different from that observed at saturation: the highest adsorption capacity is found for DM2C. This fact can be attributed to the well-known high adsorption affinity of carbonbased materials towards aromatic species. Comparatively, the adsorption capacity of DaY zeolite at such low pressures is much lower than those of DM2C and MIL-101(Cr).

Another important characteristic of the adsorbents used for the preconcentration of BTEX compounds in ambient air is their hydrophobicity. To characterize this property, the water adsorption isotherms were measured (Figure 2 (f)). It results that DM2C and DaY are highly hydrophobic and therefore have a low water adsorption $\left(<0.1 \mathrm{~g} \mathrm{~g}^{-1}\right)$ over a wide relative humidity range up to $60 \%$ (water relative pressure of 0.6 at $25^{\circ} \mathrm{C}$ ). In contrast, MIL-101(Cr) shows a moderate water uptake up to $\mathrm{RH} \sim 35 \%\left(p / p_{0} \sim 0.35\right)$, but at higher pressure a sharp increase in the adsorbed amount is observed. This behavior suggests that in the case of MIL-101(Cr), water molecules present in the ambient air at $\mathrm{RH}$ above $35 \%$ will strongly compete with BTEX species during adsorption, resulting in a less efficient preconcentration performance (see below).

However, it should be kept in mind that all the results presented in this section were obtained at equilibrium from single component adsorption experiments, and that the performance of the gas micro-preconcentrator is also highly dependent on the adsorption-desorption kinetics and the gas composition.

3.3. BTEX detection performance with the microanalytical prototype. In this section, we present results concerning the effect of the experimental conditions, in particular desorption time and relative humidity, on the detection and identification of BTEX compounds in the mixture. Figure 3 illustrates the dynamic response normalized per milligram of adsorbent $(\mathrm{S} / \mathrm{m})$, of the microsystem for the detection of a BTEX mixture with and without adsorbent in the gas micropreconcentrator for adsorption and desorption times equal to 5 and 2 min, respectively, and under nearly dry conditions (2\% $\mathrm{RH}$ at $25^{\circ} \mathrm{C}$ ). These first results confirm that the device is able to selectively detect all the VOCs in the mixture in a short time, $\sim 11 \mathrm{~min}$.

The discrimination of each compound is attributed to the use of the GC micro-column prior to the resistive gas sensor. As expected, the response of each compound was significantly enhanced by using an adsorbent in the gas micropreconcentrator. The appearance of residual peaks after a second injection indicates that the desorption process is not complete under the conditions used. The presence of these peaks is related to the adsorption affinity of the compounds with the porous materials. Indeed, the higher the affinity, the 
more difficult it will be to desorb the compounds from the porous structure of the adsorbents.

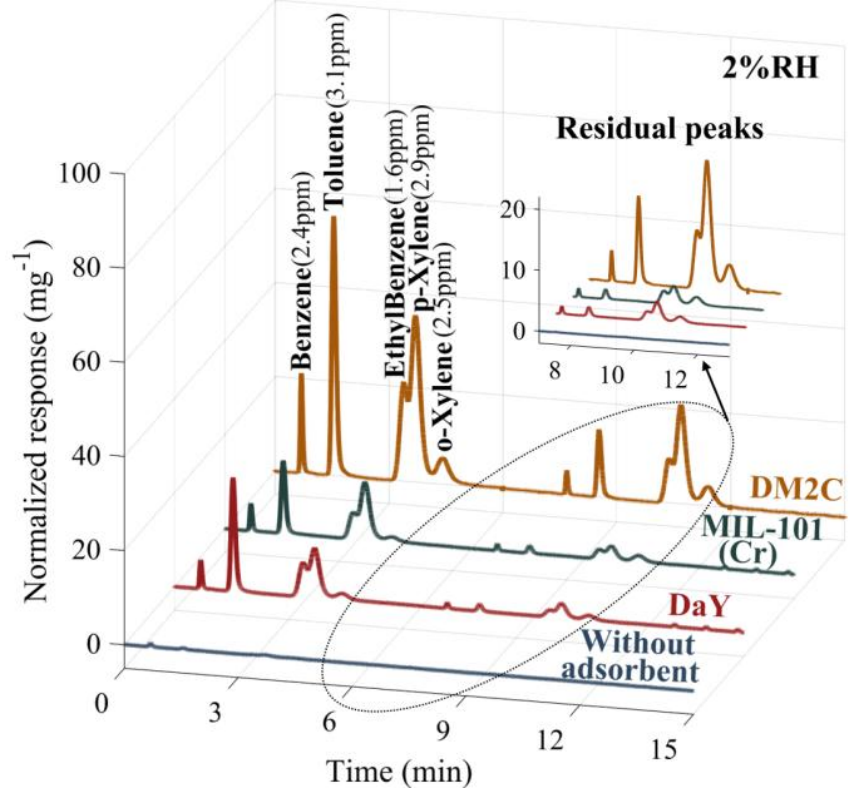

Figure 3. Dynamic normalized response, normalized per milligram of adsorbent, of the micro-system for the detection of BTEX in nearly dry air $\left(2 \% \mathrm{RH}\right.$ at $\left.25{ }^{\circ} \mathrm{C}\right)$ with and without adsorbent in the gas micro-preconcentrator (desorption time equal to $2 \mathrm{~min}$ ).

For all tests, an adsorption time of 5 min was applied and the concentrations of the BTEX compounds were 2.35, 3.08, 1.67, 2.50 and $2.88 \mathrm{ppm}$ for benzene, toluene, ethylbenzene, orthoand para-xylene, respectively. From the normalized dynamic responses shown in Figure 3 and normalized per mg of adsorbent, these peaks are most visible for DM2C, suggesting that the adsorption affinity is the highest for this material. This result is in line with the toluene adsorption isotherm at low pressure (see insert in Figure 2 (e)). Despite this high affinity for the compounds, DM2C exhibits the best performance for the preconcentration of BTEX since the response intensity for all compounds is the highest from the first desorption cycle. As previously mentioned, the interconnected texture of DM2C favors access to the micropores, which are responsible for the surface area and therefore the BTEX adsorption capacity, compared to the other adsorbents with higher BET area and micropore volume (see Table 1).

Desorption time is the key factor determining the detection performance of each compound. To be effective, the system should detect each BTEX simultaneously with the maximum possible response. Figure 4 (a) depicts the influence of desorption time on the response of each compound in dry air for the DM2C material.

As can be seen in Figure 4 (a), the desorption of benzene is very fast compared to that of the other compounds in the mixture since the maximum response was obtained with a short desorption time (less than $0.5 \mathrm{~min}$ ). With a longer desorption time, the response of benzene decreases rapidly indicating a rapid desorption from the adsorbent. The response of the other adsorbates increases gradually up to $2.5 \mathrm{~min}$, except for toluene, for which starts to decrease after a desorption time equal to $1.5 \mathrm{~min}$. This indicates that all of these benzene-derived compounds are more strongly adsorbed than benzene and therefore need more time to completely desorb from the adsorbents. Figure S1 demonstrates that the other materials (DaY and MIL-101(Cr)) have the same behavior. These different desorption rates of BTEX compounds can be explained by both diffusional and thermodynamic factors. The diffusion of BTEX within the porous structure of the adsorbents depends on the size of the molecule in relation to the size of the pores and their connectivity. Even though the selected VOCs exhibit similar kinetic diameters, benzene is the smallest molecule in this mixture, and hence its diffusion within the porous structure of the adsorbents is faster than that of the other compounds. On the contrary, a molecule such as ortho-xylene, exhibiting a larger kinetic diameter, will have more difficulties to enter and exit the microporosity of the adsorbents. The interaction strength of the species with the adsorbents also strongly contributes to the observed trend. Given the non-polar character of these adsorbents, the main contribution to the interactions comes from Van der Waals forces, which depend on molecular polarizabilities. Indeed, the polarizabilities of the studied species vary in the following order: o-xylene ethylbenzene $\sim$ p-xylene $>$ toluene $>$ benzene (see Table 2) [41]. A similar order is observed for the variation of the response of these BTEX species as a function of desorption time in our micro-analytical device (Figure 4 (a)). These different behaviors explain the disparity in desorption rate between benzene and the rest of the compounds.

Thus, a compromise is needed to obtain the highest response for each compound. In nearly dry air, a desorption time equal to $2 \mathrm{~min}$ seems to be a good compromise to identify each chemical compound with a high response. The impact of humidity on the preconcentration performance of the system was also investigated since the relative humidity of indoor air usually varies between 30 and $60 \%$ [43]. The electrical signals presented in Figure 4 (b) show the real-time responses of the micro-system for humidity values of 30 and $60 \% \mathrm{RH}$ at $25^{\circ} \mathrm{C}$ compared to nearly dry air $\left(2 \% \mathrm{RH}\right.$ at $\left.25^{\circ} \mathrm{C}\right)$ after a desorption time of $2 \mathrm{~min}$. It is well-known that the presence of water vapor affects the adsorption-desorption process.

Table 2. Comparison of polarizability $(\alpha)$ and kinetic diameter $(\sigma)$ of benzene, toluene, ethylbenzene, p-xylene, o-xylene and water [41].

\begin{tabular}{|c|c|c|}
\hline Molecule & $\mathbf{1 0}^{\mathbf{3}} \boldsymbol{\alpha ( \mathbf { n m } ^ { \mathbf { 3 } } )}$ & $\boldsymbol{\sigma}(\mathbf{n m})$ \\
\hline Benzene & $10-10.7$ & 0.535 \\
\hline Toluene & $11.8-12.3$ & 0.525 \\
\hline Ethylbenzene & 14.2 & 0.580 \\
\hline p-Xylene & $13.7-14.9$ & 0.580 \\
\hline o-Xylene & $14.1-14.9$ & 0.680 \\
\hline Water & 1.44 & 0.265 \\
\hline
\end{tabular}

In the presence of humidity in the mixture, the responses of each compound decrease significantly compared to the responses in nearly dry air, for all the adsorbents used. As an example, for DM2C, the presence of humidity $(60 \% \mathrm{RH}$ at 25 ${ }^{\circ} \mathrm{C}$ ) in the mixture made the desorption process faster for all compounds (see Figure 4 (c)). In particular, the disparity previously noticed in dry air (see again Figure 4 (a)) was reduced and all compounds desorbed in a shorter time. The same behavior was observed for the other adsorbents (Figure S2). 
(a)
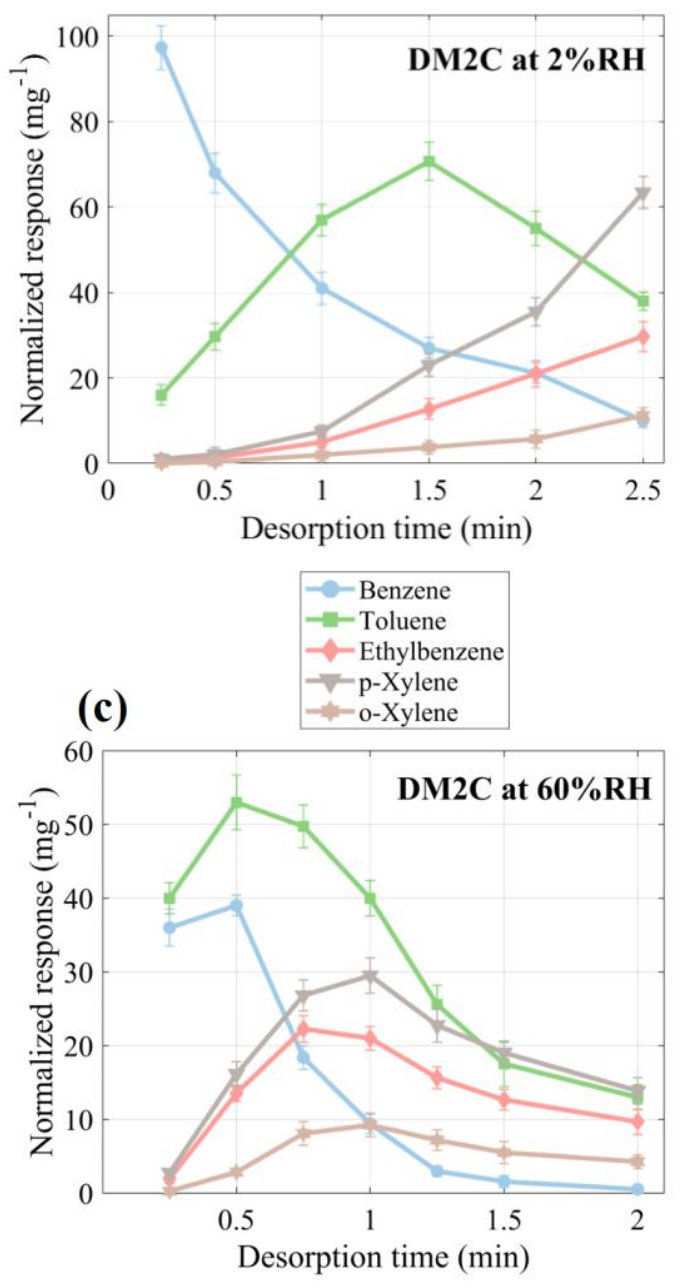

(b)
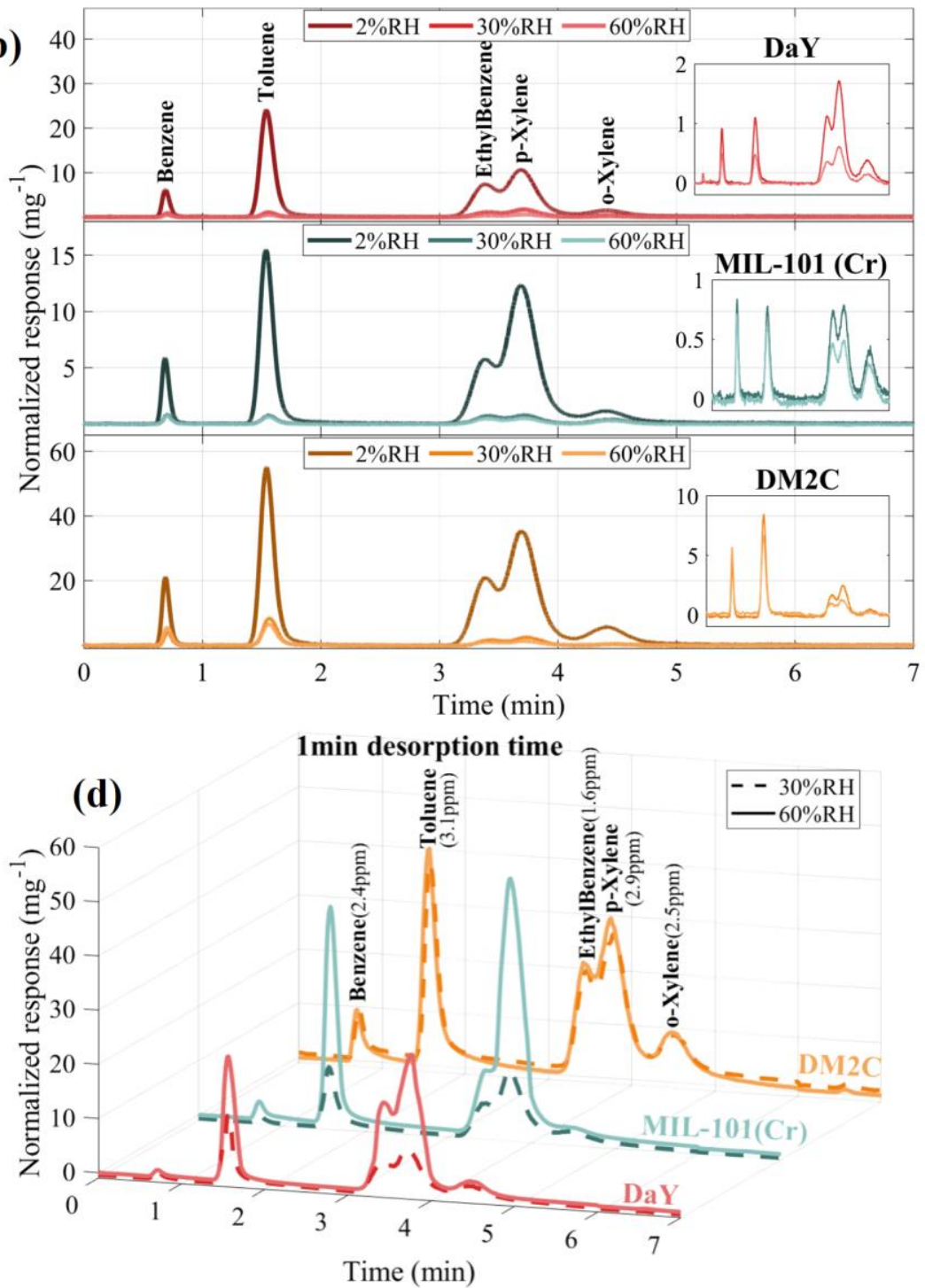

Figure 4. (a) Evolution of the response for each compound in nearly dry air $\left(2 \% \mathrm{RH}\right.$ at $\left.25^{\circ} \mathrm{C}\right)$ as a function of desorption time for the DM2C adsorbent. (b) Dynamic normalized response of the micro-system for the detection of BTEX as a function of humidity for each adsorbent using a desorption time of $2 \mathrm{~min}$; inserts show, in more details, the dynamic responses for 30 and $60 \% \mathrm{RH}$ at 25 ${ }^{\circ} \mathrm{C}$. (c) Evolution of the response for each compound under $60 \% \mathrm{RH}$ at $25{ }^{\circ} \mathrm{C}$ as a function of desorption time for the DM2C adsorbent. (d) Dynamic normalized response of the micro-system for the detection of BTEX as a function of humidity for each adsorbent using a desorption time of $1 \mathrm{~min}$. For all tests, an adsorption time of $5 \mathrm{~min}$ was applied and the concentrations of the BTEX compounds were $2.35,3.08,1.67,2.50$ and $2.88 \mathrm{ppm}$ for benzene, toluene, ethylbenzene, ortho- and para-xylene, respectively.

This can be explained by the competitive adsorption of water and BTEX on the surface of the adsorbents, occurring in multicomponent adsorption-desorption processes. Faster desorption under humid conditions allows for shorter desorption times. Thus, Figure 4 (d) displays the response of the micro-system for 30 and $60 \% \mathrm{RH}$ at $25{ }^{\circ} \mathrm{C}$ after reducing the desorption time to $1 \mathrm{~min}$. It follows that, under humid conditions, a desorption time of 1 min leads to better results for all adsorbents compared to the optimal condition under nearly dry air (2 min desorption time). We observed that, regardless of the hydrophobic or hydrophilic nature of the selected adsorbents, the preconcentration performance was slightly reduced or, in certain cases, even improved in a humid environment. In addition, the analysis time was re- duced to $\sim 10$ min instead of $\sim 11$ min in the case of a nearly dry atmosphere.

The electrical responses to different concentrations of BTEX diluted in humid air $\left(60 \% \mathrm{RH}\right.$ at $\left.25^{\circ} \mathrm{C}\right)$ were also measured in order to evaluate the analytical performance of the microsystem as a function of the adsorbent used. The electrical signals presented in Figure 5 (a) show the real-time responses of the micro-system for different dilutions of the initial BTEX mixture (see experimental conditions) and under 60 $\% \mathrm{RH}$ at $25^{\circ} \mathrm{C}$.

As expected, the amplitude of the responses decreases with an increasing dilution ratio. For DaY and MIL-101(Cr), although benzene, toluene, ethylbenzene and para-xylene 
(a)

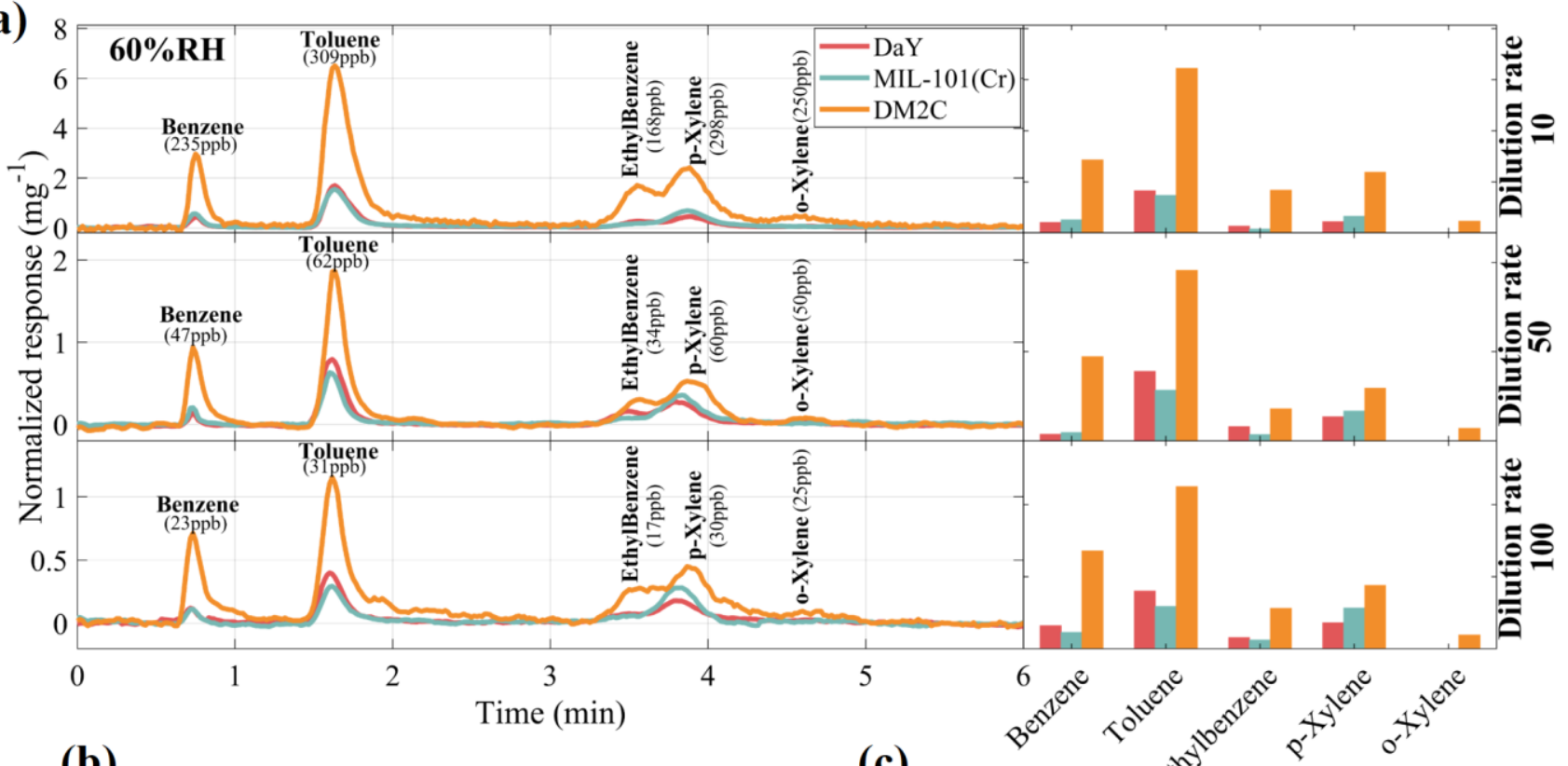

(b)

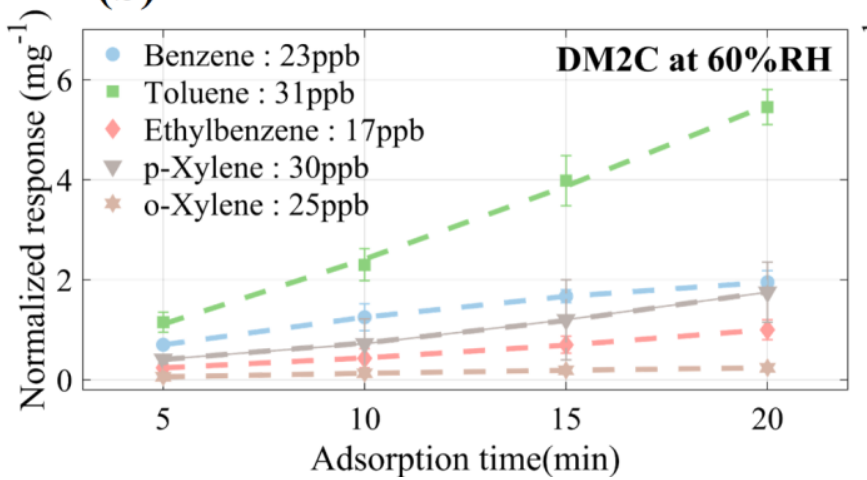

(c)

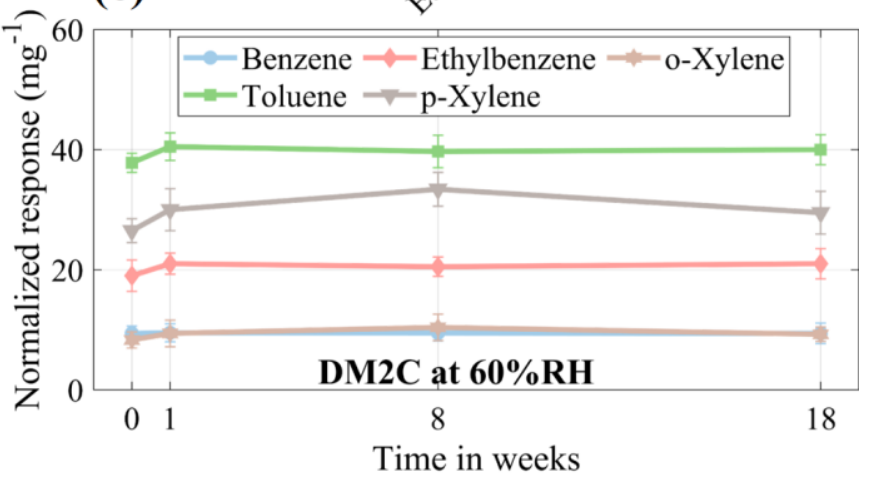

Figure 5. (a) Dynamic normalized response of the micro-system as a function of BTEX concentration and amplitude of the response of each VOC with an adsorption time of $5 \mathrm{~min}$ and a desorption time of 1 min in humid air $\left(60 \% \mathrm{RH}\right.$ at $\left.25{ }^{\circ} \mathrm{C}\right)$. (b) Influence of adsorption time on the response of each VOC ( 1 min desorption time) for the DM2C material under $60 \% \mathrm{RH}$ at $25{ }^{\circ} \mathrm{C}$. (c) Study of the repeatability and stability of the DM2C adsorbent during 18 weeks of use in humid air $\left(60 \% \mathrm{RH}\right.$ at $\left.25^{\circ} \mathrm{C}\right)$.

Table 3. Limit of detection (LOD) extrapolated for each compound for the DM2C adsorbent in the presence of $60 \% \mathrm{RH}$ at $25{ }^{\circ} \mathrm{C}$.

\begin{tabular}{|c|c|c|c|c|c|}
\hline Adsorption time (min) & Benzene (ppb) & Toluene (ppb) & Ethylbenzene (ppb) & p-Xylene (ppb) & o-Xylene (ppb) \\
\hline $\mathbf{5}$ & $12 \pm 2$ & $10 \pm 1$ & $14 \pm 2$ & $11 \pm 2$ & $21 \pm 3$ \\
\hline $\mathbf{1 0}$ & $8 \pm 1.4$ & $4 \pm 0.5$ & $8 \pm 1.3$ & $5 \pm 1.1$ & $15 \pm 2$ \\
\hline $\mathbf{2 0}$ & $4 \pm 1$ & $<1 \pm 0.2$ & $3 \pm 0.7$ & $1 \pm 0.6$ & $8 \pm 1.5$ \\
\hline
\end{tabular}

The DM2C adsorbent offers the best detection performance as it was still possible to identify each compound in the mixture with concentrations as low as $23.5,30.8,16.7,25$ and 28.8 ppb of benzene, toluene, ethylbenzene, ortho- and para-xylene, respectively, and in the presence of humidity. It is worth noting that these concentrations are the lowest that our experimental set-up can generate (dilution of 100 from the initial concentrations of BTEX compounds).

Based on these studies, DM2C appears to be a very promising adsorbent for the preconcentration of indoor air VOCs, even in the presence of high levels of relative humidity. Moreover, the efficiency of DM2C can be further increased by using longer adsorption times. Figure 5 (b) depicts the relationship between the adsorption time and the response of each compound for the DM2C material under $60 \% \mathrm{RH}$ at $25{ }^{\circ} \mathrm{C}$. It is interesting to note that the response increases progressively as the adsorption time increases from 5 to $20 \mathrm{~min}$, suggesting that the detection limit of the species can be lowered to a sub-ppb level. Indeed, the detection limit of the system can be extrapolated from the calibration curve as long as the sensor signal is greater than or equal to 3 times the noise (the average noise level of the gas sensor is 0.01). Table 3 lists the extrapolated LODs obtained for each compound. It follows that by increasing the 
adsorption time, we can detect all BTEX compounds present in indoor air with a high sensitivity.

Finally, we performed repeatability tests as well as stability tests of the micro-system over time. Figure 5 (c) represents the evolution of the response, for each BTEX compound, obtained with the same DM2C-based gas micro-preconcentrator, in humid air $\left(60 \% \mathrm{RH}\right.$ at $\left.25^{\circ} \mathrm{C}\right)$ and during 18 weeks of use. It can be observed that the normalized conductance for each VOC compound shows a slight variation (between $5 \%$ and 10 $\%$ ), which may be related to the drift of the metal oxide-based gas sensor. Based on these results, over a period of 4 months and more than 500 tests that include thermal cycles, DM2C presents excellent stability and repeatability, which makes it a very reliable adsorbent for the detection of trace VOCs in indoor air under realistic relative humidity conditions.

Although in the last decade, efforts have been made to develop compact detection devices [34, 44 - 47], very few studies have been reported in the literature on the use of silicon-etched preconcentrator and GC micro-column units combined with a metal oxide-based gas sensor for in situ detection of BTEX in humid air. However, we can cite the work of Zampolli et al. [35] who identified a sub-ppb benzene concentration using a sampling time of $55 \mathrm{~min}$. It is noteworthy that the miniaturized prototype presented in this study allows to achieve analysis performances comparable to those presented in the literature but with shorter analysis times ( $10 \mathrm{~min})$ and in humid conditions.

\section{CONCLUSION}

In this study, we characterized the efficiency of three nanoporous solids (DaY zeolite, MIL-101(Cr) MOF and DM2C, a tannin-derived carbon) for the preconcentration of trace amounts of BTEX compounds in indoor air. Each material was placed in three different gas micro-preconcentrators that are part of a micro-analytical prototype also containing a GC micro-column and a miniaturized metal oxide-based gas sensor. With the initial BTEX mixture containing 2.35, 3.08, 1.67, 2.50 and $2.88 \mathrm{ppm}$ of benzene, toluene, ethylbenzene, ortho- and para-xylene, respectively, all the selected adsorbents allowed the detection of BTEX compounds under both dry and humid conditions (up to $60 \% \mathrm{RH}$ at $25{ }^{\circ} \mathrm{C}$ ). The response of the micro-analytical prototype to each BTEX species was evaluated as a function of desorption time and the variation was found to be molecule dependent. Due to this effect, an optimal desorption time was determined in order to detect all species. In the presence of humidity in the BTEX mixture, this desorption time was lowered to about $1 \mathrm{~min}$. After diluting the initial mixture by a factor of up to 10 , only the DM2C material remained efficient as preconcentration adsorbent for detecting the BTEX species. Thus, we have shown that the excellent preconcentration performance of the DM2C material allows the identification of each indoor air pollutant with concentrations as low as 23.5, 30.8, 16.7, 25 and $28.8 \mathrm{ppb}$ of benzene, toluene, ethylbenzene, ortho- and para-xylene, respectively, and in a short analysis time, of approximately $10 \mathrm{~min}$. DM2C also showed excellent stability and repeatability over a period of 4 months and more than 500 tests.

\section{ASSOCIATED CONTENT}

\section{Supporting Information}

The Supporting Information is available free of charge on the ACS Publications website.
Pdf file including: Figure S1 showing the influence of desorption time on the response of each compound in nearly dry air for DaY and MIL-101(Cr) materials; Figure S2 that depict the influence of desorption time on the response in the presence of humidity $(60 \%$ $\mathrm{RH}$ at $25^{\circ} \mathrm{C}$ ) in the mixture for DaY and MIL-101(Cr) materials.

\section{AUTHOR INFORMATION}

\section{Corresponding Authors}

* Jean-Baptiste Sanchez, Institut FEMTO-ST, UMR 6174, Université de Bourgogne - Franche-Comté, France. orcid.org/00000002-3303-0973; Phone: +33 36308 24 93; Email: jbsanche@femto-st.fr

* Vanessa Fierro, Institut Jean Lamour, UMR 7198 Université de Lorraine, France. orcid.org/0000-0001-7081-3697; Phone: + 333 727496 77; Email: vanessa.fierro@univ-lorraine.fr

\section{Author Contributions}

A. El Mohajir performed the BTEX detection experiments, analyzed the data and designed the figures. J. Castro-Gutiérrez synthesized the DM2C material. R.L.S. Canevesi, V. Fierro, I. Bezverkhyy and G. Weber carried out the adsorption-desorption experiments and analyzed the data. Jean-Baptiste Sanchez conceived the presented idea, analyzed the data and took the lead in writing the manuscript. All authors contributed to the interpretation of the results, discussion and writing of the manuscript. All authors gave their approval to the final version of the manuscript.

\section{ACKNOWLEDGMENT}

The authors would like to express their gratitude to the Bourgogne Franche-Comté Region, the European fund FEDER and the EUR EIPHI for financial support through the project DECOLAIR. This work was partially supported by the French RENATECH network and its FEMTO-ST technological facility. FEMTO Engineering realized the silicon-etched structures (https://www.femto-engineering.fr/). The authors acknowledge Emmanuel Dordor from the Joint Mechanics Department of Femto-ST for his contribution to the design of the device. The authors from IJL also acknowledge the financial support through the TALiSMAN project, funded by ERDF (No. 2019-000214).

\section{REFERENCES}

[1] Baghani, A. N.; Sorooshian, A.; Heydari, M.; Sheikhi, R.; Golbaz, S.; Ashournejad, Q.; Kermani, M.; Golkhorshidi, F.; Barkhordari, A.; Jafari, A. J.; Delikhoon, M.; Shahsavani, A. A Case Study of BTEX Characteristics and Health Effects by Major Point Sources of Pollution during Winter in Iran. Environmental Pollution 2019, 247, 607617.

[2] Bolden, A. L.; Kwiatkowski, C. F.; Colborn, T. New Look at BTEX: Are Ambient Levels a Problem? Environ. Sci. Technol. 2015, 49 (9), 5261-5276.

[3] Dehghani, M.; Fazlzadeh, M.; Sorooshian, A.; Tabatabaee, H. R.; Miri, M.; Baghani, A. N.; Delikhoon, M.; Mahvi, A. H.; Rashidi, M. Characteristics and Health Effects of BTEX in a Hot Spot for Urban Pollution. Ecotoxicology and Environmental Safety 2018, 155, 133143.

[4] Masekameni, M. D.; Moolla, R.; Gulumian, M.; Brouwer, D. Risk Assessment of Benzene, Toluene, Ethyl Benzene, and Xylene Concentrations from the Combustion of Coal in a Controlled Laboratory Environment. International Journal of Environmental Research and Public Health 2019, 16 (1), 95.

[5] Ji, Y.; Gao, F.; Wu, Z.; Li, L.; Li, D.; Zhang, H.; Zhang, Y.; Gao, J.; Bai, Y.; Li, H. A Review of Atmospheric Benzene Homologues in China: Characterization, Health Risk Assessment, Source Identification and Countermeasures. J Environ Sci (China) 2020, 95, 225-239. 
[6] Truc, V. T. Q.; Kim Oanh, N. T. Roadside BTEX and Other Gaseous Air Pollutants in Relation to Emission Sources. Atmospheric Environment 2007, 41 (36), 7685-7697.

[7] Miri, M.; Rostami Aghdam Shendi, M.; Ghaffari, H. R.; Ebrahimi Aval, H.; Ahmadi, E.; Taban, E.; Gholizadeh, A.; Yazdani Aval, M.; Mohammadi, A.; Azari, A. Investigation of Outdoor BTEX: Concentration, Variations, Sources, Spatial Distribution, and Risk Assessment. Chemosphere 2016, 163, 601-609.

[8] Guo, H.; Lee, S. C.; Li, W. M.; Cao, J. J. Source Characterization of BTEX in Indoor Microenvironments in Hong Kong. Atmospheric Environment 2003, 37 (1), 73-82.

[9] Hazrati, S.; Rostami, R.; Farjaminezhad, M.; Fazlzadeh, M. Preliminary Assessment of BTEX Concentrations in Indoor Air of Residential Buildings and Atmospheric Ambient Air in Ardabil, Iran. Atmospheric Environment 2016, 132, 91-97.

[10] Demirel, G.; Özden, Ö.; Döğeroğlu, T.; Gaga, E. O. Personal Exposure of Primary School Children to BTEX, NO2 and Ozone in Eskişehir, Turkey: Relationship with Indoor/Outdoor Concentrations and Risk Assessment. Science of The Total Environment 2014, 473474, 537-548.

[11] Topp, R.; Cyrys, J.; Gebefügi, I.; Schnelle-Kreis, J.; Richter, K.; Wichmann, H.-E.; Heinrich, J. Indoor and Outdoor Air Concentrations of BTEX and NO2: Correlation of Repeated Measurements. $J$. Environ. Monit. 2004, 6 (10), 807-812.

[12] Ohura, T.; Amagai, T.; Shen, X.; Li, S.; Zhang, P.; Zhu, L. Comparative Study on Indoor Air Quality in Japan and China: Characteristics of Residential Indoor and Outdoor VOCs. Atmospheric Environment 2009, 43 (40), 6352-6359.

[13] Raysoni, A. U.; Stock, T. H.; Sarnat, J. A.; Chavez, M. C.; Sarnat, S. E.; Montoya, T.; Holguin, F.; Li, W.-W. Evaluation of VOC Concentrations in Indoor and Outdoor Microenvironments at Near-Road Schools. Environmental Pollution 2017, 231, 681-693.

[14] Parra, M. A.; Elustondo, D.; Bermejo, R.; Santamaría, J. M. Quantification of Indoor and Outdoor Volatile Organic Compounds (VOCs) in Pubs and Cafés in Pamplona, Spain. Atmospheric Environment 2008, 42 (27), 6647-6654.

[15] Zhong, L.; Su, F.-C.; Batterman, S. Volatile Organic Compounds (VOCs) in Conventional and High Performance School Buildings in the U.S. International Journal of Environmental Research and Public Health 2017, 14 (1), 100.

[16] Dewulf, J.; Langenhove, H. V.; Wittmann, G. Analysis of Volatile Organic Compounds Using Gas Chromatography. TrAC Trends in Analytical Chemistry 2002, 21 (9), 637-646.

[17] Baimatova, N.; Kenessov, B.; Koziel, J. A.; Carlsen, L.; Bektassov, M.; Demyanenko, O. P. Simple and Accurate Quantification of BTEX in Ambient Air by SPME and GC-MS. Talanta 2016 , $154,46-52$

[18] Xu, J.; Szyszkowicz, M.; Jovic, B.; Cakmak, S.; Austin, C. C.; Zhu, J. Estimation of Indoor and Outdoor Ratios of Selected Volatile Organic Compounds in Canada. Atmospheric Environment 2016, 141, 523-531.

[19] Gregis, G.; Sanchez, J.-B.; Bezverkhyy, I.; Guy, W.; Berger, F.; Fierro, V.; Bellat, J.-P.; Celzard, A. Detection and Quantification of Lung Cancer Biomarkers by a Micro-Analytical Device Using a Single Metal Oxide-Based Gas Sensor. Sensors and Actuators B: Chemical 2018, 255, 391-400.

[20] Mohsen, Y.; Lahlou, H.; Sanchez, J.-B.; Berger, F.; Bezverkhyy, I.; Weber, G.; Bellat, J.-P. Development of a Micro-Analytical Prototype for Selective Trace Detection of Orthonitrotoluene. Microchemical Journal 2014, 114, 48-52.

[21] Dettmer, K.; Engewald, W. Adsorbent Materials Commonly Used in Air Analysis for Adsorptive Enrichment and Thermal Desorption of Volatile Organic Compounds. Anal Bioanal Chem 2002, 373 (6), 490-500.

[22] Eyer, S.; Stadie, N. P.; Borgschulte, A.; Emmenegger, L.; Mohn, J. Methane Preconcentration by Adsorption: A Methodology for Materials and Conditions Selection. Adsorption 2014, 20 (5-6), 657666.

[23] Mohsen, Y.; Sanchez, J.-B.; Berger, F.; Lahlou, H.; Bezverkhyy, I.; Fierro, V.; Weber, G.; Celzard, A.; Bellat, J.-P. Selection and Characterization of Adsorbents for the Analysis of an Explosive-
Related Molecule Traces in the Air. Sensors and Actuators B: Chemical 2013, 176, 124-131.

[24] Almazán, F.; Pellejero, I.; Morales, A.; Urbiztondo, M. A.; Sesé, J.; Pina, M. P.; Santamaría, J. Zeolite Based Microconcentrators for Volatile Organic Compounds Sensing at Trace-Level: Fabrication and Performance. J. Micromech. Microeng. 2016, 26 (8), 084010.

[25] Matisová, E.; Škrabáková, S. Carbon Sorbents and Their Utilization for the Preconcentration of Organic Pollutants in Environmental Samples. Journal of Chromatography A 1995, 707 (2), 145-179.

[26] Gu, Z.-Y.; Wang, G.; Yan, X.-P. MOF-5 Metal-Organic Framework as Sorbent for In-Field Sampling and Preconcentration in Combination with Thermal Desorption GC/MS for Determination of Atmospheric Formaldehyde. Anal. Chem. 2010, 82 (4), 1365-1370.

[27] Xie, L.-H.; Liu, X.-M.; He, T.; Li, J.-R. Metal-Organic Frameworks for the Capture of Trace Aromatic Volatile Organic Compounds. Chem 2018, 4 (8), 1911-1927.

[28] Vellingiri, K.; Szulejko, J. E.; Kumar, P.; Kwon, E. E.; Kim, K.H.; Deep, A.; Boukhvalov, D. W.; Brown, R. J. C. Metal Organic Frameworks as Sorption Media for Volatile and Semi-Volatile Organic Compounds at Ambient Conditions. Scientific Reports 2016, 6 (1), 27813.

[29] Woellner, M.; Hausdorf, S.; Klein, N.; Mueller, P.; Smith, M. W.; Kaskel, S. Adsorption and Detection of Hazardous Trace Gases by Metal-Organic Frameworks. Advanced Materials 2018, 30 (37), 1704679

[30] Yang, K.; Sun, Q.; Xue, F.; Lin, D. Adsorption of Volatile Organic Compounds by Metal-Organic Frameworks MIL-101: Influence of Molecular Size and Shape. Journal of Hazardous Materials 2011, 195, 124-131.

[31] Shafiei, M.; Alivand, M. S.; Rashidi, A.; Samimi, A.; MohebbiKalhori, D. Synthesis and Adsorption Performance of a Modified Micro-Mesoporous MIL-101(Cr) for VOCs Removal at Ambient Conditions. Chemical Engineering Journal 2018, 341, 164-174.

[32] Khan, N. A.; Hasan, Z.; Jhung, S. H. Adsorptive Removal of Hazardous Materials Using Metal-Organic Frameworks (MOFs): A Review. Journal of Hazardous Materials 2013, 244-245, 444-456.

[33] Wang, D.; Wu, G.; Zhao, Y.; Cui, L.; Shin, C.-H.; Ryu, M.-H.; Cai, J. Study on the Copper(II)-Doped MIL-101(Cr) and Its Performance in VOCs Adsorption. Environ Sci Pollut Res 2018, 25 (28), 28109-28119.

[34] Lara-lbeas, I.; Rodríguez-Cuevas, A.; Andrikopoulou, C.; Person, V.; Baldas, L.; Colin, S.; Le Calvé, S. Sub-Ppb Level Detection of BTEX Gaseous Mixtures with a Compact Prototype GC Equipped with a Preconcentration Unit. Micromachines 2019, 10 (3), 187.

[35] Zampolli, S.; Elmi, I.; Mancarella, F.; Betti, P.; Dalcanale, E.; Cardinali, G. C.; Severi, M. Real-Time Monitoring of Sub-Ppb Concentrations of Aromatic Volatiles with a MEMS-Enabled Miniaturized Gas-Chromatograph. Sensors and Actuators B: Chemical 2009, 141 (1), 322-328.

[36] Malouche, A.; Blanita, G.; Lupu, D.; Bourgon, J.; Nelayah, J.; Zlotea, C. Hydrogen Absorption in $1 \mathrm{Nm}$ Pd Clusters Confined in MIL-101(Cr). J. Mater. Chem. A 2017, 5 (44), 23043-23052.

[37] Castro-Gutiérrez, J.; Sanchez-Sanchez, A.; Ghanbaja, J.; Díez, N.; Sevilla, M.; Celzard, A.; Fierro, V. Synthesis of Perfectly Ordered Mesoporous Carbons by Water-Assisted Mechanochemical SelfAssembly of Tannin. Green Chem. 2018, 20 (22), 5123-5132.

[38] Jagiello, J.; Olivier, J. P. Carbon Slit Pore Model Incorporating Surface Energetical Heterogeneity and Geometrical Corrugation. Adsorption 2013, 19 (2-4), 777-783.

[39] Bellat, J.-P.; Bezverkhyy, I.; Weber, G.; Royer, S.; Averlant, R.; Giraudon, J.-M.; Lamonier, J.-F. Capture of Formaldehyde by Adsorption on Nanoporous Materials. Journal of Hazardous Materials 2015, 300, 711-717.

[40] Thommes, M.; Kaneko, K.; Neimark, A. V.; Olivier, J. P.; Rodriguez-Reinoso, F.; Rouquerol, J.; Sing, K. S. W. Physisorption of Gases, with Special Reference to the Evaluation of Surface Area and Pore Size Distribution (IUPAC Technical Report). Pure and Applied Chemistry 2015, 87 (9-10), 1051-1069.

[41] Li, J.-R.; Kuppler, R. J.; Zhou, H.-C. Selective Gas Adsorption and Separation in Metal-Organic Frameworks. Chem. Soc. Rev. 2009, 38 (5), 1477-1504. 
[42] Castro-Gutiérrez, J.; De Oliveira Jardim, E.; Canevesi, R. L. S.; Silvestre-Albero, J.; Kriesten, M.; Thommes, M.; Celzard, A.; Fierro, V. Molecular Sieving of Linear and Branched C6 Alkanes by TanninDerived Carbons. Carbon 2021, 174, 413-422.

[43] Arundel, A. V.; Sterling, E. M.; Biggin, J. H.; Sterling, T. D. Indirect Health Effects of Relative Humidity in Indoor Environments. Environ. Health Perspect. 1986, 65, 351-361.

[44] Nasreddine, R.; Person, V.; Serra, C. A.; Le Calvé, S. Development of a Novel Portable Miniaturized GC for Near Real-Time Low Level Detection of BTEX. Sensors and Actuators B: Chemical 2016, 224, 159-169.

[45] Wang, J.; Bryant-Genevier, J.; Nuñovero, N.; Zhang, C.; Kraay, B.; Zhan, C.; Scholten, K.; Nidetz, R.; Buggaveeti, S.; Zellers, E. T.
Compact Prototype Microfabricated Gas Chromatographic Analyzer for Autonomous Determinations of VOC Mixtures at Typical Workplace Concentrations. Microsyst Nanoeng 2018, 4 (1), 1-10.

[46] Sun, J.; Xue, N.; Wang, W.; Wang, H.; Liu, C.; Ma, T.; Li, T.; Tan, T. Compact Prototype GC-PID System Integrated with Micro PC and Micro GC Column. J. Micromech. Microeng. 2019, 29 (3), 035008.

[47] Sun, J.; Geng, Z.; Xue, N.; Liu, C.; Ma, T. A Mini-System Integrated with Metal-Oxide-Semiconductor Sensor and Micro-Packed Gas Chromatographic Column. Micromachines (Basel) 2018, 9 (8), 408. 